\title{
The Study of Kinetic Properties and Analytical Pyrolysis of Coconut Shells
}

\author{
Mahir Said, ${ }^{1}$ Geoffrey John, ${ }^{1}$ Cuthbert Mhilu, ${ }^{1}$ and Samwel Manyele ${ }^{2}$ \\ ${ }^{1}$ Department of Mechanical and Industrial Engineering, University of Dar es Salaam, Dar es Salaam, Tanzania \\ ${ }^{2}$ Department of Chemical and Mining Engineering, University of Dar es Salaam, Dar es Salaam, Tanzania \\ Correspondence should be addressed to Mahir Said; mahir@udsm.ac.tz
}

Received 22 May 2015; Revised 29 July 2015; Accepted 5 August 2015

Academic Editor: Hasan Ferdi Gercel

Copyright (c) 2015 Mahir Said et al. This is an open access article distributed under the Creative Commons Attribution License, which permits unrestricted use, distribution, and reproduction in any medium, provided the original work is properly cited.

\begin{abstract}
The kinetic properties of coconut shells during pyrolysis were studied to determine its reactivity in ground form. The kinetic parameters were determined by using thermogravimetric analyser. The activation energy was $122.780 \mathrm{~kJ} / \mathrm{mol}$. The pyrolysis products were analyzed using pyrolysis gas chromatography/mass spectrometry (Py-GC/MS). The effects of pyrolysis temperature on the distribution of the pyrolytic products were assessed in a temperature range between $673 \mathrm{~K}$ and $1073 \mathrm{~K}$. The set time for pyrolysis was $2 \mathrm{~s}$. Several compounds were observed; they were grouped into alkanes, acids, ethers and alcohols, esters, aldehydes and ketones, furans and pyrans, aromatic compounds, and nitrogen containing compounds. The product compositions varied with temperature in that range. The highest gas proportion was observed at high temperature while the acid proportion was observed to be highest in coconut shells, thus lowering the quality of bio-oil. It has been concluded that higher pyrolysis temperature increases the amount of pyrolysis products to a maximum value. It has been recommended to use coconut shell for production of gas, instead of production of bio-oil due to its high proportion of acetic acid.
\end{abstract}

\section{Introduction}

The consumption of biomass fuel is increasing worldwide due to concerns over energy shortage of fossil fuels and due to increasing of carbon dioxide emission. Sustainable production of biomass fuel from forest and agriculture products can displace fossil fuels. Although burning of biomass fuels releases carbon dioxide, the regrowth of the sustainable managed trees offset that release, a property not possible with fossil fuels. This forest fuel can supply energy virtually without net contribution to greenhouse gas levels. Many African countries depend on agricultural activities and have abundant forest resources and agrowaste that can benefit them in energy production.

Tanzania is one among the African countries, which is located in the equatorial region. It has large source of biomass material. The agricultural sector has about 10 million hectares [1]. Biomass makes $88 \%$ of the primary energy consumption in Tanzania [2].

The biomass always contains high moisture content, irregular shapes and size, and low bulk density, when collected from the field. This makes the biomass have low energy density and become expensive and difficult to manage. It is dried and used for combustion directly, but in developed countries after drying the biomass is densified for making pellets [3].

The biomass material constitutes mainly cellulose, hemicellulose, and lignin. The variation proportions of these constituents in different biomass species have been studied in the past, the hemicellulose varies from 25 to $40 \% \mathrm{wt}$, cellulose varies from 30 to $40 \% \mathrm{wt}$, and lignin is between 5 and $15 \% \mathrm{wt}$ [4]. The main products during decomposition of lignin are aromatic compounds, while the decomposition products of cellulose and hemicellulose are linear compounds which have the same functional groups.

Although biomass is used as a solid fuel, the demand of liquid and gaseous fuel has made several researchers convert biomass to liquid and gaseous fuel through relevant processes. Pyrolysis is one among the thermal processes that is used to convert solid biomass to liquid fuel. It is the process by which biomass is heated without oxidizing agent. Three main products are obtained as gas, liquid, and solid phases. 
TABLE 1: Proximate, ultimate analysis, and higher heating value of biomass materials.

\begin{tabular}{|c|c|c|c|c|c|c|c|c|}
\hline \multirow[b]{2}{*}{$\begin{array}{l}\text { MC } \\
(\% w t) \\
\end{array}$} & \multicolumn{2}{|c|}{ Proximate analysis } & \multicolumn{5}{|c|}{ Ultimate analysis } & \multirow[b]{2}{*}{ Higher heating value $(\mathrm{MJ} / \mathrm{kg})$} \\
\hline & $\begin{array}{c}\text { Volatile matter }{ }^{\mathrm{db}} \\
\qquad(\% \mathrm{wt})\end{array}$ & $\begin{array}{c}\text { Fixed carbon }{ }^{\mathrm{db}} \\
\qquad(\% \mathrm{wt})\end{array}$ & $\begin{array}{l}\operatorname{Ash}^{\mathrm{db}} \\
(\% \mathrm{wt})\end{array}$ & $\begin{array}{c}\mathrm{C} \\
(\% \mathrm{wt})\end{array}$ & $\begin{array}{c}\mathrm{H} \\
(\% \mathrm{wt})\end{array}$ & $\begin{array}{c}\mathrm{O}^{\mathrm{db}} \\
(\% \mathrm{wt})\end{array}$ & $\begin{array}{c}\mathrm{N} \\
(\% \mathrm{wt})\end{array}$ & \\
\hline 10.70 & 79.18 & 20.26 & 0.56 & 47.94 & 6.41 & 45.56 & 0.10 & 17.35 \\
\hline
\end{tabular}

Note: $\mathrm{db}=$ dry basis; $\mathrm{df}=$ by difference.

The gas mainly contains carbon dioxide, carbon monoxide, methane, and hydrogen [5]. The solid part is char, which is made up of fixed carbon and ash. The third and main product is liquid, also known as bio-oil, which contains several compounds. The compounds formed depend on the type of biomass species, elemental composition of biomass, and pyrolysis conditions [4].

In this study, the formations of compounds which are constituted in bio-oil were studied by using PY-GC/MS at different pyrolysis temperature, the biomass material used being coconut shells.

\section{Methodology}

2.1. Biomass Preparation. The coconut shells were obtained from local farmers of Tanzania. The coconut shells were obtained after removing husks and kernels of the coconut. The coconut shells were sun-dried until they became brittle, followed by grinding to less than $0.25 \mathrm{~mm}$ to increase surface area yielding bio-oil during pyrolysis [6]. The grinding machine used was Retsch GmbH 5657 HAAN, type SK1, Nor 72307.

\subsection{Coconut Shell Characterization}

2.2.1. Determination of Ultimate and Proximate Analysis. Important characteristics of biomass materials were done by determining the proximate and ultimate analysis. The proximate analysis was done to observe the moisture, volatile, fixed carbon, and ash content of the biomass material. Ultimate analysis was done to observe the elemental analysis of biomass materials, such as carbon, hydrogen, oxygen, and nitrogen. The important components of fuels are carbon and hydrogen.

2.2.2. Determination of Gross Calorific Value. The gross calorific value of the biomass material was obtained by using bomb calorimeter model CAB001.AB1.C. The standard test method for biomass analysis was ASTM E870-82 [7]. These analyses are also considered for determination of combustion properties of a fuel [8].

2.2.3. Thermogravimetric Analysis. The biomass materials were dried for two hours in the oven at $378 \mathrm{~K}\left(105^{\circ} \mathrm{C}\right)$ to constant weight before subjecting the samples to thermogravimetric analysis. During thermogravimetric analysis, $20 \mathrm{mg}( \pm 0.03 \mathrm{mg})$ of biomass material was put in the crucible and then kept in the thermogravimetric analyzer type NETZSCH STA 409 PC Luxx. The TG was run under nonisothermal conditions and the temperature was raised from room temperature $303 \mathrm{~K}$ to $1100 \mathrm{~K}$ and the heating medium was nitrogen at a flow rate of $50 \mathrm{~mL} / \mathrm{min}$. The standard method used was ASTM E1131-08 [9]. The heating rate applied was $10 \mathrm{~K} / \mathrm{min}$.

2.3. Analytical Pyrolysis. The pyrolysis of biomass samples and analysis of product compositions were done by using $\mathrm{Py}-$ GC/MS (Agilent Technology 5975C, model number G3174A, serial number US12504A05). A $1 \mathrm{mg}( \pm 0.01 \mathrm{mg})$ sample of biomass material was kept on the filament and heated at a constant temperature for $2 \mathrm{~s}$. The reaction temperatures applied were $673 \mathrm{~K}\left(400^{\circ} \mathrm{C}\right), 773 \mathrm{~K}\left(500^{\circ} \mathrm{C}\right), 873 \mathrm{~K}\left(600^{\circ} \mathrm{C}\right)$, $973 \mathrm{~K}\left(700^{\circ} \mathrm{C}\right)$, and $1073 \mathrm{~K}\left(800^{\circ} \mathrm{C}\right)$; the pyrolysis medium was helium. The gas and volatiles produced during pyrolysis were analyzed by using GC/MS. The solid residues left on the filament were measured after each experiment. Each experiment was done three times to ensure it can be repeated.

\section{Results and Discussion}

3.1. Biomass Characterization. Test results of the proximate and ultimate analysis of the coconut shells and higher heating value are shown in Table 1. It has been observed that coconut shells contain high carbon about 50\%wt and hydrogen content about $6 \%$ wt. The presence of nitrogen and high amount of oxygen about $46 \%$ wt reduces the energy content of biomass materials, because these elements do not support combustion [10]. The higher heating value of coconut shell was about $17 \mathrm{MJ} / \mathrm{kg}$; this calorific value is lower than that of conventional fossil fuels such as coal which is about $30 \mathrm{MJ} / \mathrm{kg}$ [11]. Therefore, it is important to convert coconut shells to a high energy fuel through thermochemical process such as pyrolysis. The proximate, ultimate analysis and higher heating value obtained in this study are in agreement with other biomass characterization studies done [12].

Table 2 shows the cellulose, hemicellulose, and lignin of coconut shells as reported by different researchers [13, 14]. When coconut shells are compared to the other wood biomass such as pine, it has been reported that coconut shells contain higher composition of hemicellulose and small amount of cellulose [14].

3.2. Thermogravimetric (TG) Analysis of Biomass. The TG and DTG profiles of biomass sample were drawn (shown in Figures 1(a) and 1(b)). The profile is divided into three regions. The first region is formed between room temperature and $500 \mathrm{~K}$; this is due to moisture removal; there is no chemical reaction taking place in this region. The second region is devolatilization process. In this region, a high mass loss is observed; it started above $500 \mathrm{~K}$ depending on type of 


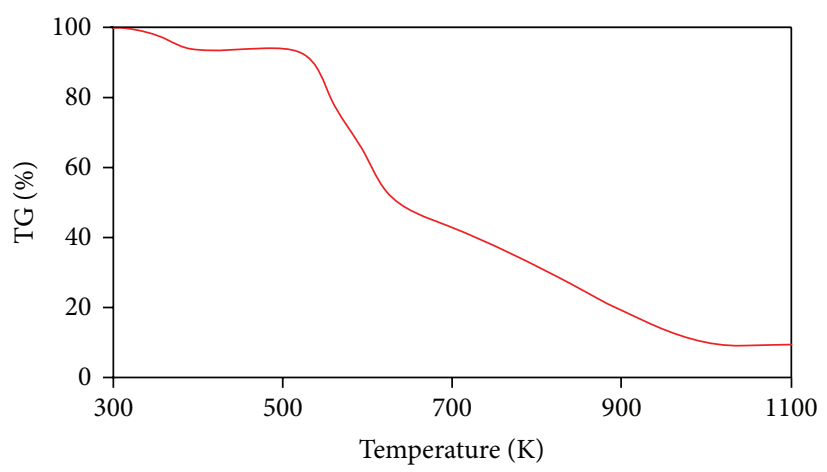

(a)

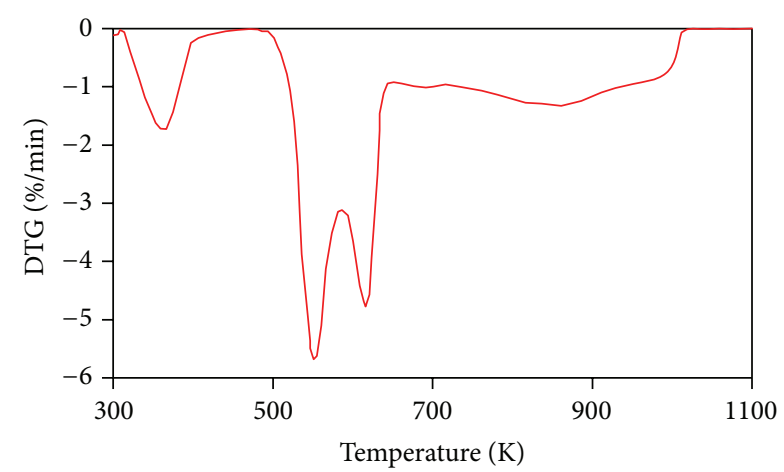

(b)

Figure 1: (a) Thermogravimetric (TG) analysis of coconut shells. (b) Differential thermogravimetric (DTG) analysis of coconut shells.

TABLE 2: Biomass composition.

\begin{tabular}{lcccc}
\hline Biomass & Cellulose & Hemicellulose & Lignin & Reference \\
\hline Coconut shells & 19.8 & 50.1 & 30.1 & {$[13]$} \\
\hline
\end{tabular}

biomass material [15]. The devolatilization of coconut shell is between $500 \mathrm{~K}$ and $1000 \mathrm{~K}$; the curve has a kink at about $600 \mathrm{~K}$ which differentiates between light and heavy volatiles [16]. The light volatiles are released at low temperature, while heavy volatiles are released at high temperature. Furthermore, the DTG (Figure 1(b)) curves show the degradation of biomass components (hemicellulose, cellulose, and lignin). The first peak shows the degradation of hemicellulose, followed by cellulose, while lignin has very short peak but wide peak which spread to overlap hemicelluloses and cellulose. However, the peaks of cellulose and hemicellulose overlap in the DTG of coconut shells, but they can be differentiated, the peak of cellulose appeared at $640 \mathrm{~K}$, and the hemicellulose peak appeared at $550 \mathrm{~K}$. The peak height of hemicellulose in coconut shells is larger than that of cellulose, since coconut shells contain higher amount of hemicellulose as shown in Table 2. The lignin degradation starts above $500 \mathrm{~K}$, but the final temperature depends on the type of the biomass material. The final temperature for lignin degradation for coconut shells is about $1000 \mathrm{~K}$. This means that the pyrolysis temperature for any biomass material should be above its final temperature of cellulose, because at that temperature all volatiles from biomass will be already removed.

The kinetic parameters were determined in order to understand the biomass degradation behavior. The method used was Coats and Redfern method ((1) and (2)). Equation (1) is applied when the thermodegradation of biomass is first order $(n=1)$ and (2) when the reaction is not first order $(n \neq 1)$ [17]. The graph in Figure 2 was obtained after solving (1), since biomass degradation was observed to fit on first order.

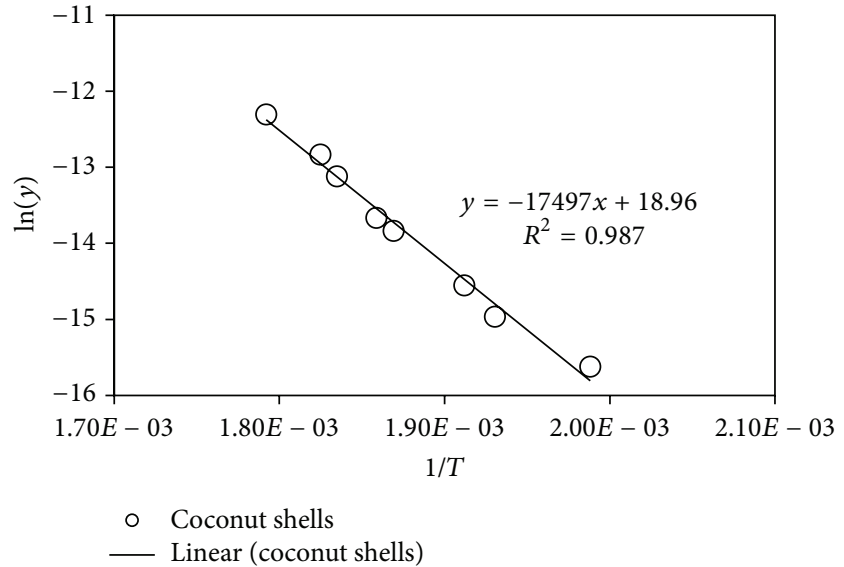

FIGURE 2: The graphs for determining kinetic parameters.

The activation energy for coconut shells is $122.780 \mathrm{~kJ} / \mathrm{mol}$, preexponential factor is $2.177 \times 10^{9} / \mathrm{s}$, and the reaction is first order. Consider

$$
\begin{aligned}
\ln (y) & =\ln \left[\frac{-\ln (1-\alpha)}{T^{2}}\right] \\
& =\ln \left[\frac{A R}{\beta E_{a}}\left(1-\frac{2 R T}{E_{a}}\right)\right]-\frac{E_{a}}{R T} \quad n=1, \\
\ln (y) & =\ln \left[\frac{(1-\alpha)^{1-n}-1}{(n-1) T^{2}}\right] \\
& =\ln \left[\frac{A R}{\beta E_{a}}\left(1-\frac{2 R T}{E_{a}}\right)\right]-\frac{E_{a}}{R T} \quad n \neq 1 .
\end{aligned}
$$

3.3. Biomass Pyrolysis by Using PY-GC/MS. PY-GC/MS uses isothermal process whereby the biomass sample is heated at a constant temperature. The PY-GC/MS cannot measure the yield of products produced, but it provides the peak area (intensity) of the products. The intensity corresponds to the amount of products produced during pyrolysis [18]. There are several chemical compounds formed during biomass 


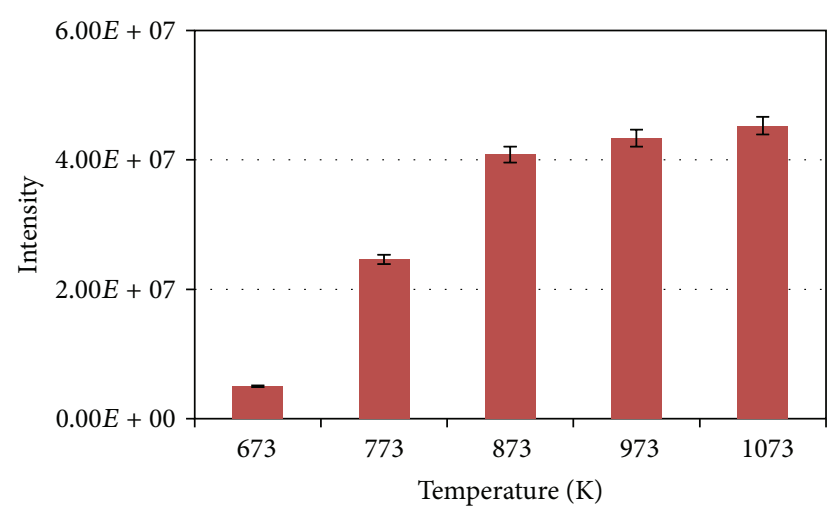

FIGURE 3: The gas production from pyrolysis of biomass.

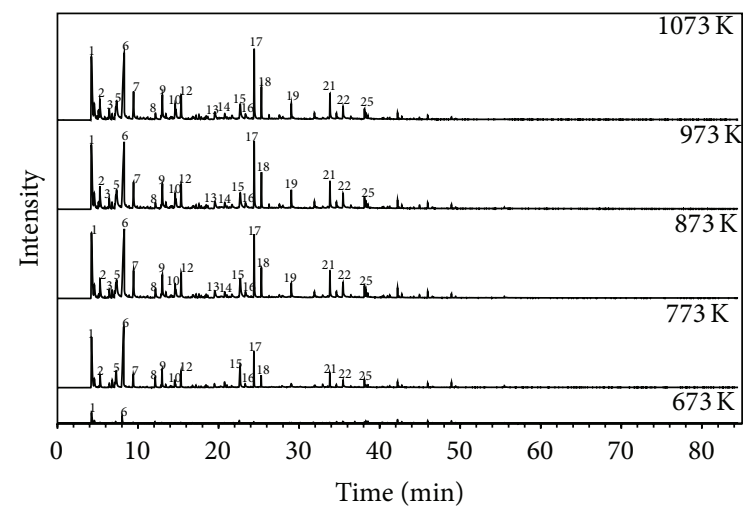

FIgURE 4: Chromatograms of pyrolysis of coconut shells at different temperatures.

pyrolysis. But the compounds that will be discussed in this study are those that vary with pyrolysis temperature according to their chromatograms. The chromatograms of biomass depend on both types of biomass and pyrolysis temperature.

The analysis of biomass pyrolysis products shows that there are several chemical compounds produced during pyrolysis. The details of chemical compounds observed during pyrolysis of biomass material are shown in the chromatograms (Figure 4). The origins of the compounds are derived from three components of biomass; these are cellulose, hemicellulose, and lignin. The products that are derived from cellulose and hemicellulose are grouped into gas, alkane, alcohol, furan, carboxylic acid, ketone, aldehyde, and pyran $[19,20]$. Phenols and benzene related compounds are derived from lignin $[21,22]$.

3.3.1. The Gas. It has been observed that the gas yield increases as pyrolysis temperature increases as shown in Figure 3, with this also being reported by other researchers such as Bridgwater [23]. The main components of the gas are carbon dioxide $\left(\mathrm{CO}_{2}\right)$, carbon monoxide $(\mathrm{CO})$, methane $\left(\mathrm{CH}_{4}\right)$, and hydrogen $\left(\mathrm{H}_{2}\right)$. The increase of the yield of gaseous products is due to decarboxylation and decarbonylation $[24,25]$.
3.3.2. Alkane. The alkane produced during biomass pyrolysis is pentane, the amount which increases with increasing temperature. The alkanes are important compounds in biooil production, since it is very combustible. The alkane is produced through a cracking of high hydrocarbons in biomass during the pyrolysis process and the yield is between 2 and $6 \%$, while in catalytic pyrolysis the yield can reach up to $24.66 \%$ [26].

3.3.3. Acids. The acid observed is only acetic acid. The acids reduce the $\mathrm{pH}$ of the bio-oil produced during pyrolysis [27]. The acids are produced when hemicellulose and cellulose are decomposing $[5,28]$. The acids are formed by removing acetyl groups in xylose [29], but Güllü and Demirbaş [30]reported that acids are also formed due to decomposition of all three wood components (cellulose, hemicellulose, and lignin). Furthermore, high proportion of acid content (about 20\%) was observed in coconut shells attributable to its high amount of hemicellulose, while the other biomass produces acetic acid in the range of 5 to 15\% [31] as observed in Table 3 and in the DTG curve (Figure 1(b)). The detailed analysis of acids is shown in Table 3 .

3.3.4. Ethers, Esters, and Alcohols. The ethers, esters, and alcohols were produced during biomass pyrolysis as shown in Table 3. The ethers produced are in the form of oxirane, methyl-,(S)- and 1,3-dioxolane,2-3 ethenyl-4-methyl-. The alcohol is in the form of propyl alcohol. The esters formed during pyrolysis of biomass are acetic acid methyl ester and propanoic acid,2-oxo-,methyl ester. The formation of ethers, esters, and alcohols is due to decomposition of cellulose, hemicellulose, and lignin [29].

3.3.5. Furans and Pyrans. Furans and pyrans are formed from all biomass during thermal decomposition. They are derived from cellulose, while pyrans are produced from the destruction of hemicelluloses $[32,33]$. The furfural and $2 \mathrm{H}$-pyran-2,6(3H)-dione were produced at high temperature only. The proportions of compounds were not affected by increasing temperature as shown in Table 3.

3.3.6. Aldehydes and Ketones. The aldehydes and ketones are derived from the degradation of cellulose, as proposed by Piskorz et al. [34]. Aldehydes are formed through dehydration of cellulose, while Gao et al. [29] reported that ketones are formed by breaking the molecular bonds between $\mathrm{C} 2$ and $\mathrm{C} 3$ of glucose monomers and hemiacetal group loops. Generally, the temperature has least effect on the production of aldehydes and ketones. The aldehyde compound formed during pyrolysis of coconut shells is acetaldehyde hydroxyl, which is produced at all temperature ranges. While the compounds for ketones are 2-propanone, 1-hydroxy-, 1,2cyclopentanedione, 2-pentanone, and 3-pentanone. They are produced at high temperature. The temperature has less effect on production of ketone compounds in all biomass materials.

3.3.7. Aromatic Compounds. The main compounds formed during decomposition of lignin are aromatic hydrocarbons 
TABLE 3: Compounds produced during biomass pyrolysis.

\begin{tabular}{|c|c|c|c|c|c|c|c|}
\hline $\mathrm{PN}$ & Compounds & $\mathrm{RT}, \mathrm{min}$ & $673 \mathrm{~K}$ & $773 \mathrm{~K}$ & $873 \mathrm{~K}$ & $973 \mathrm{~K}$ & $1073 \mathrm{~K}$ \\
\hline & Pentane & & & & & & \\
\hline \multirow[t]{2}{*}{2} & Pentane (wt, \%) & 5.321 & 2.10 & 2.92 & 3.18 & 3.97 & 3.18 \\
\hline & Acids, alcohol, esters, and ethers & & & & & & \\
\hline 6 & Acetic acid (wt, \%) & 8.077 & 20.41 & 20.66 & 19.56 & 18.31 & 17.52 \\
\hline 8 & Propargyl alcohol (wt, \%) & 12.118 & 2.74 & 3.1 & 1.88 & 1.13 & 1.18 \\
\hline 9 & Acetic acid, methyl ester (wt, \%) & 13.021 & 3.92 & 4.23 & 4.5 & 4.18 & 4.75 \\
\hline 10 & Propanoic acid, 2-oxo-methyl ester (wt, \%) & 14.611 & - & - & 1.69 & 1.96 & 1.82 \\
\hline 11 & Oxirane, methyl-,(S)-(wt, \%) & 14.732 & - & - & 1.17 & 1.41 & 1.5 \\
\hline \multirow[t]{2}{*}{24} & 1,3-Dioxolane, 2-ethenyl-4-methyl-(wt, \%) & 36.955 & 3.29 & - & - & - & - \\
\hline & Furans and pyrans & & & & & & \\
\hline 12 & Furfural (wt, \%) & 15.337 & - & 3.41 & 4.06 & 4.53 & 3.8 \\
\hline \multirow[t]{2}{*}{16} & 2H-Pyran-2,6(3H)-dione (wt, \%) & 23.401 & - & - & 1.50 & 1.28 & 1.20 \\
\hline & Aldehydes and ketones & & & & & & \\
\hline 3 & 2-Pentanone (wt, \%) & 6.467 & - & - & 1.79 & 1.7 & 1.89 \\
\hline 4 & 3-Pentanone (wt, \%) & 6.838 & - & 1.92 & 0.99 & 1.01 & 0.99 \\
\hline 5 & Acetaldehyde hydroxy-(wt, \%) & 7.290 & 4.15 & 6.85 & 6.1 & 7.07 & 7.72 \\
\hline 7 & 2-Propanone, 1-hydroxy-(wt, \%) & 9.478 & - & 3.65 & 4.8 & 4.19 & 4.41 \\
\hline \multirow[t]{2}{*}{13} & 1,2-Cyclopentanedione (wt, \%) & 19.598 & - & - & 2.33 & 2.27 & 2.23 \\
\hline & Aromatic compounds & & & & & & \\
\hline 17 & Phenol (wt, \%) & 24.380 & 6.7 & 6.17 & 7.98 & 7.58 & 8.32 \\
\hline 18 & Phenol,2-methoxy-(wt, \%) & 25.305 & - & 2.12 & 4.07 & 4.69 & 3.7 \\
\hline 19 & Creosol (wt, \%) & 29.058 & - & - & 2.18 & 1.95 & 2 \\
\hline 21 & 2-Methoxy-4-vinylphenol (wt, \%) & 33.863 & - & 2.78 & 3.31 & 3.6 & 3.21 \\
\hline 23 & Phenol,2,6-dimethoxy-(wt, \%) & 35.438 & 2.57 & 2.18 & 1.89 & 2.25 & 2.44 \\
\hline 25 & trans-Isoeugenol (wt, \%) & 38.126 & - & 1.48 & 1.03 & 1.13 & 1.24 \\
\hline 26 & 3-Hydroxy-4-methoxybenzoic acid (wt, \%) & 38.298 & 3.27 & - & - & - & - \\
\hline 27 & Vanillin (wt, \%) & 38.567 & 3.18 & - & - & - & - \\
\hline 28 & Phenol,2,6-dimethoxy-4-(2-propenyl)-(wt, \%) & 42.768 & 1.87 & - & - & - & - \\
\hline 29 & 2-Propionic acid, 3-(4-hydroxy-3-methoxyphenyl (wt, \%) & 45.987 & 3.33 & - & - & - & - \\
\hline \multirow[t]{2}{*}{30} & 4-((1E)-3-Hydroxy-1-propenyl)-2-methoxyphenol (wt, \%) & 48.928 & 3.32 & - & - & - & - \\
\hline & Nitrogen containing compounds & & & & & & \\
\hline 14 & 2-Imidazolidinone (wt, \%) & 20.814 & - & 1.45 & 1.20 & 1.18 & 1.08 \\
\hline 15 & 2-Methyliminoperhydro-1,3-oxazine (wt, \%) & 22.597 & 4.68 & 7.61 & 5.56 & 4.31 & 4.14 \\
\hline
\end{tabular}

such as phenolic, guaiacyl, and syringyl compounds. The product distribution and the yield of products are strongly dependent on the type of biomass [35]. These show that there is no uniform trend for methoxy phenols; this was also observed by Niemz et al. [36]. The relation of phenol formation is not the same to all biomass; each type of biomass behaves differently. Brebu and Vasile [35] reported that guaiacol and syringols are intermediate degradation products, they are decreasing with increasing pyrolysis temperature, and they form vinyl phenols by cleavage of the O-C (alkyl) and $\mathrm{O}-\mathrm{C}$ (aryl) bonds and other small molecular compounds. The proportions of aromatic compounds are shown in Table 3. Coconut shell has a high proportion of aromatic compounds at lower temperature.

3.3.8. Nitrogen Compounds. Furthermore, it has been observed that there is a formation of organic compounds containing nitrogen as shown in Table 3. This is the evidence that nitrogen in the biomass is in the form of compounds such as protein $[37,38]$. Literature has reported the formation of nitrogen containing compounds during pyrolysis $[37,38]$. The analysis of different studies $[37,38]$ revealed that the formation of nitrogen containing compounds during pyrolysis is due to amino groups present in the biomass. Ammonia and nitrogen oxides can be released during pyrolysis; this means the compounds containing nitrogen were decomposed into ammonia and other low molecular weight compounds. In this study, it has been observed that the nitrogen containing compounds decrease by increasing reaction temperature. The nitrogen containing compounds formed were 2-imidazolidinone and 2-methyliminoperhydro-1,3-oxirane.

3.4. The Formation of Aromatic Compound during Pyrolysis. Table 3 revealed that the aromatic compounds that are formed at low temperature $(<773 \mathrm{~K})$ are different to 


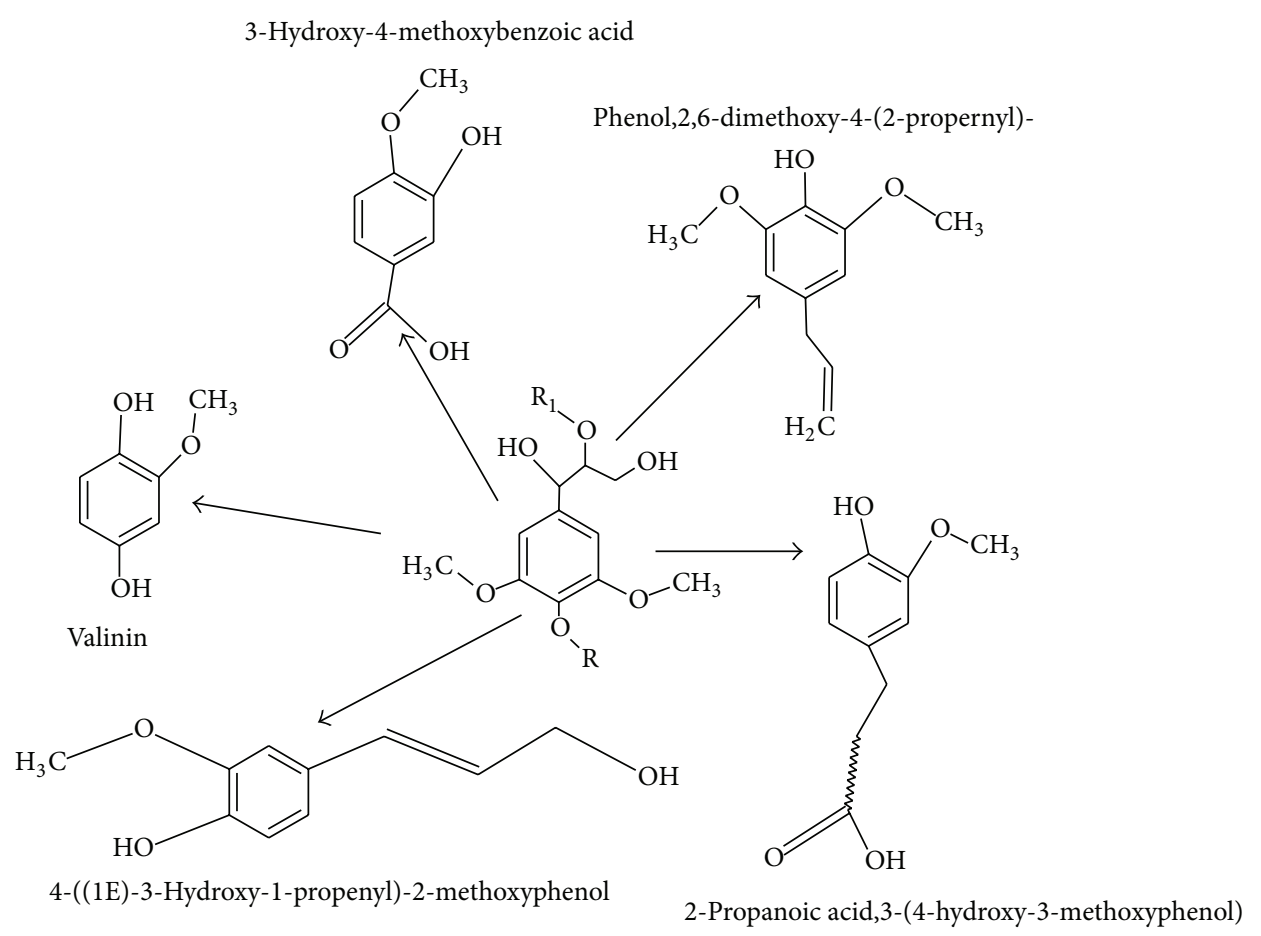

Figure 5: The schematic diagram of the lignin decomposition at low temperature ( $<773 \mathrm{~K})$.

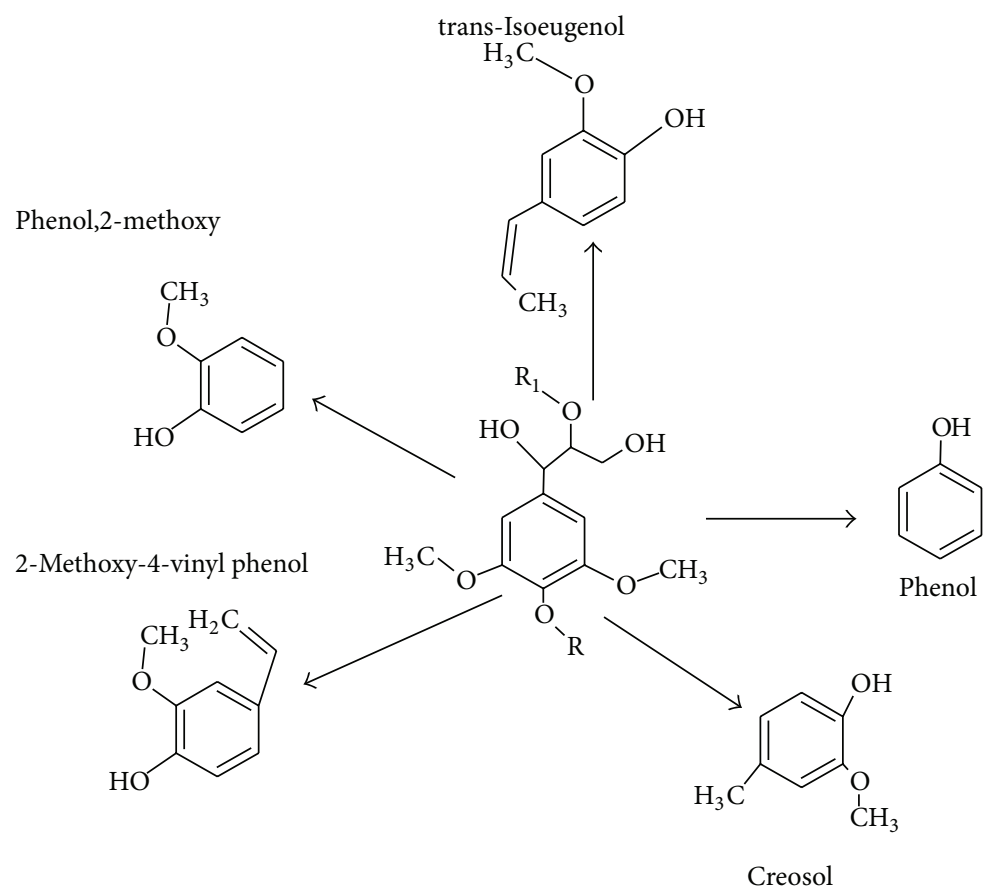

Figure 6: The schematic diagram of the lignin decomposition at high temperature ( $>773 \mathrm{~K})$.

those formed at higher temperature $(>773 \mathrm{~K})$. The aromatic compounds are produced due to the decomposition of lignin.

When lignin is heated at low temperature, the compounds formed are 4-((1E)-3-hydroxy-1-propenyl)-2-methoxyphenol, 2-propernoic acid,3-(4-hydroxy)-3-methoxyphenyl, Phenol-2-6-dimethoxy-4-(2-propenyl), 3-hydroxy-4-methoxybenzoic acid and valinin. Generally, these aromatic compounds have long braches as shown in Figure 5. This can be explained that the temperature was not high enough to break the bond of linear compound from benzene ring.

The aromatic compounds that are formed at high temperature were phenol, trans-isoeugenol, phenol,2-methoxy, and 2-methoxy-4-vinylphenol as shown in Figure 6. These aromatic compounds have shorter branches of linear 
compounds than the former ones formed at low temperature. This can be seen that the linear compounds that attached to the benzene rings are removed when the high temperature is applied to the lignin. The linear compounds that have been removed from lignin increase the amount of other liner compounds such as, shown in Figure 4, acetic acid methyl ester, propanoic acid,2-oxo-, methyl ester, oxirane, methyl-,(S)-, 2pentanone, acetaldehyde hydroxy-, 1,2-cyclopentanedione, and some gaseous compounds as shown in Table 3. Also, it has been observed that the amount of phenol increases as temperature increases for the same reasons.

\section{Conclusion}

The characterization of coconut shell shows that the activation energy of coconut shell was $122.780 \mathrm{~kJ} / \mathrm{mol}$; this resembles other biomass materials which are in the range of 60 to $200 \mathrm{~kJ} / \mathrm{mol}$ [39].

The incremental reaction temperature during pyrolysis increases the intensity of the pyrolysis products, which reveal the increment of the amount of the products. Some compounds only appear at a certain temperature range. There are several compounds that were formed at low temperature $(673 \mathrm{~K})$ such as vanillin, phenol,2,6-dimethoxy, and 4-((1E)3-hydroxy-1-propenyl)-2-methoxyphenol, and creosol. Some compounds were also produced at high temperature (above $773 \mathrm{~K}$ ) such as 1,2-cyclopentanedione and $2 \mathrm{H}$-pyran-2,6(3H)dione.

It has been observed that amounts of some linear compounds and phenol increase at high temperature due to the removal of linear compounds of aromatic compounds.

The coconut shell cannot be a good source of liquid (bio-oil) fuel, since it has a high proportion of acetic acid and nitrogen containing compounds, lower pentane and aldehyde, and lower furans, but it contains higher proportion of phenolic compounds. Instead, it can be a good source of gaseous fuel (such as syngas).

\section{Nomenclature}

A: Preexponential factor $\left(\mathrm{s}^{-1}\right)$

$E_{a}:$ Activation energy $(\mathrm{J} / \mathrm{mol})$

$R:$ Gas constant $(\mathrm{J} / \mathrm{molK})$

T: Absolute temperature $(\mathrm{K})$

$\beta$ : Heating rate $(\mathrm{K} / \mathrm{s})$

$\alpha$ : Mass ratio.

\section{Conflict of Interests}

The authors declare that there is no conflict of interests regarding the publication of this paper.

\section{Acknowledgments}

The authors wish to thank Swedish International Development Cooperation Agency (Sida) and Swedish Energy Agency for their generous financial and material support rendered to allow this research work to be conducted.

\section{References}

[1] L. Wilson, W. Yang, W. Blasiak, G. R. John, and C. F. Mhilu, "Thermal characterization of tropical biomass feedstocks," Energy Conversion and Management, vol. 52, no. 1, pp. 191-198, 2011.

[2] M. A. Kusekwa, Biomass Conversion to Energy in Tanzania: A Critique, New Developments in Renewable Energy, P. H. Arman, Ed., InTech, 2003.

[3] R. G. Fernández, C. P. García, A. G. Lavín, J. L. B. de las Heras, and J. J. Pis, "Influence of physical properties of solid biomass fuels on the design and cost of storage installations," Waste Management, vol. 33, no. 5, pp. 1151-1157, 2013.

[4] D. Mohan, C. U. Pittman Jr., and P. H. Steele, "Pyrolysis of wood/biomass for bio-oil: a critical review," Energy \& Fuels, vol. 20, no. 3, pp. 848-889, 2006.

[5] S. Yaman, "Pyrolysis of biomass to produce fuels and chemical feedstocks," Energy Conversion and Management, vol. 45, no. 5, pp. 651-671, 2004.

[6] J. Shen, X.-S. Wang, M. Garcia-Perez, D. Mourant, M. J. Rhodes, and C.-Z. Li, "Effects of particle size on the fast pyrolysis of oil mallee woody biomass," Fuel, vol. 88, no. 10, pp. 1810-1817, 2009.

[7] ASTM, E870-82. Standard Test Methods for Analysis of Wood Fuels, ASTM International, West Conshohocken, Pa, USA, 2006.

[8] A. Demirbas, "Combustion characteristics of different biomass fuels," Progress in Energy and Combustion Science, vol. 30, no. 2, pp. 219-230, 2004.

[9] ASTM International, E1131-08, Standard Method for Compositional Analysis by Thermogravimetry, ASTM International, West Conshohocken, Pa, USA, 2014.

[10] S. Czernik and A. V. Bridgwater, "Overview of applications of biomass fast pyrolysis oil," Energy \& Fuels, vol. 18, no. 2, pp. 590598, 2004.

[11] S. A. Channiwala and P. P. Parikh, "A unified correlation for estimating HHV of solid, liquid and gaseous fuels," Fuel, vol. 81, no. 8, pp. 1051-1063, 2002.

[12] A. J. Tsamba, W. Yang, and W. Blasiak, "Pyrolysis characteristics and global kinetics of coconut and cashew nut shells," Fuel Processing Technology, vol. 87, no. 6, pp. 523-530, 2006.

[13] W. M. A. W. Daud and W. S. W. Ali, "Comparison on pore development of activated carbon produced from palm shell and coconut shell," Bioresource Technology, vol. 93, no. 1, pp. 63-69, 2004.

[14] M. J. Ramsden and F. S. R. Blake, "A kinetic study of the acetylation of cellulose, hemicellulose and lignin components in wood," Wood Science and Technology, vol. 31, no. 1, pp. 45-50, 1997.

[15] M. Carrier, A. Loppinet-Serani, D. Denux et al., "Thermogravimetric analysis as a new method to determine the lignocellulosic composition of biomass," Biomass and Bioenergy, vol. 35, no. 1, pp. 298-307, 2011.

[16] K. M. Isa, S. Daud, N. Hamidin, K. Ismail, S. A. Saad, and F. H. Kasim, "Thermogravimetric analysis and the optimisation of bio-oil yield from fixed-bed pyrolysis of rice husk using response surface methodology (RSM)," Industrial Crops and Products, vol. 33, no. 2, pp. 481-487, 2011.

[17] M. K. Baloch, M. J. Z. Khurram, and G. F. Durrani, "Application of different methods for the thermogravimetric analysis of polyethylene samples," Journal of Applied Polymer Science, vol. 120, no. 6, pp. 3511-3518, 2011. 
[18] Q. Lu, X.-C. Yang, C.-Q. Dong, Z.-F. Zhang, X.-M. Zhang, and X.-F. Zhu, "Influence of pyrolysis temperature and time on the cellulose fast pyrolysis products: analytical Py-GC/MS study," Journal of Analytical and Applied Pyrolysis, vol. 92, no. 2, pp. 430-438, 2011.

[19] I. Pastorova, R. E. Botto, P. W. Arisz, and J. J. Boon, "Cellulose char structure: a combined analytical Py-GC-MS, FTIR, and NMR study," Carbohydrate Research, vol. 262, no. 1, pp. 27-47, 1994.

[20] D. K. Shen, S. Gu, and A. V. Bridgwater, "Study on the pyrolytic behaviour of xylan-based hemicellulose using TG-FTIR and Py-GC-FTIR," Journal of Analytical and Applied Pyrolysis, vol. 87, no. 2, pp. 199-206, 2010.

[21] J. Ralph and R. D. Hatfield, "Pyrolysis-GC-MS characterization of forage materials," Journal of Agricultural and Food Chemistry, vol. 39, no. 8, pp. 1426-1437, 1991.

[22] C. A. Mullen and A. A. Boateng, "Catalytic pyrolysis-GC/MS of lignin from several sources," Fuel Processing Technology, vol. 91, no. 11, pp. 1446-1458, 2010.

[23] A. V. Bridgwater, "Review of fast pyrolysis of biomass and product upgrading," Biomass and Bioenergy, vol. 38, pp. 68-94, 2012.

[24] P. A. Horne and P. T. Williams, "Influence of temperature on the products from the flash pyrolysis of biomass," Fuel, vol. 75, no. 9, pp. 1051-1059, 1996.

[25] P. T. Williams and S. Besler, "The influence of temperature and heating rate on the slow pyrolysis of biomass," Renewable Energy, vol. 7, no. 3, pp. 233-250, 1996.

[26] E. Pütün, F. Ateş, and A. E. Pütün, "Catalytic pyrolysis of biomass in inert and steam atmospheres," Fuel, vol. 87, no. 6, pp. 815-824, 2008.

[27] K. Sipilä, E. Kuoppala, L. Fagernäs, and A. Oasmaa, "Characterization of biomass-based flash pyrolysis oils," Biomass and Bioenergy, vol. 14, no. 2, pp. 103-113, 1998.

[28] X.-S. Zhang, G.-X. Yang, H. Jiang, W.-J. Liu, and H.-S. Ding, "Mass production of chemicals from biomass-derived oil by directly atmospheric distillation coupled with co-pyrolysis," Scientific Reports, vol. 3, article 1120, 2013.

[29] N. Gao, A. Li, C. Quan, L. Du, and Y. Duan, "TG-FTIR and PyGC/MS analysis on pyrolysis and combustion of pine sawdust," Journal of Analytical and Applied Pyrolysis, vol. 100, pp. 26-32, 2013.

[30] D. Güllü and A. Demirbaş, "Biomass to methanol via pyrolysis process," Energy Conversion and Management, vol. 42, no. 11, pp. 1349-1356, 2001.

[31] E. Kantarelis, W. Yang, and W. Blasiak, "Production of liquid feedstock from biomass via steam pyrolysis in a fluidized bed reactor," Energy \& Fuels, vol. 27, no. 8, pp. 4748-4759, 2013.

[32] S. Wang, X. Guo, T. Liang, Y. Zhou, and Z. Luo, "Mechanism research on cellulose pyrolysis by Py-GC/MS and subsequent density functional theory studies," Bioresource Technology, vol. 104, pp. 722-728, 2012.

[33] R. J. Evans, C. C. Elam, M. Looker, and M. Nimlos, "Formation of aromatic hydrocarbons due to partial oxidation reactions in biomass gasification," in Proceedings of the 218th National Meeting of the American Chemical Society, Abstracts of Papers of the American Chemical Society, p. U810, New Orleans, La, USA, August 1999.

[34] J. Piskorz, D. Radlein, and D. S. Scott, "On the mechanism of the rapid pyrolysis of cellulose," Journal of Analytical and Applied Pyrolysis, vol. 9, no. 2, pp. 121-137, 1986.
[35] M. Brebu and C. Vasile, "Thermal degradation of lignin-a review," Cellulose Chemistry \& Technology, vol. 44, no. 9, pp. 353-363, 2010.

[36] P. Niemz, T. Hofmann, and T. Rétfalvi, "Investigation of chemical changes in the structure of thermally modified wood," Maderas: Ciencia y Tecnologia, vol. 12, no. 2, pp. 69-78, 2010.

[37] C.-Z. Li and L. L. Tan, "Formation of $\mathrm{NO}_{\mathrm{x}}$ and $\mathrm{SO}_{\mathrm{x}}$ precursors during the pyrolysis of coal and biomass. Part III. Further discussion on the formation of $\mathrm{HCN}$ and $\mathrm{NH}_{3}$ during pyrolysis," Fuel, vol. 79, no. 15, pp. 1899-1906, 2000.

[38] Q. Ren, C. Zhao, X. Chen, L. Duan, Y. Li, and C. Ma, " $\mathrm{NO}_{x}$ and $\mathrm{N}_{2} \mathrm{O}$ precursors $\left(\mathrm{NH}_{3}\right.$ and $\left.\mathrm{HCN}\right)$ from biomass pyrolysis: co-pyrolysis of amino acids and cellulose, hemicellulose and lignin," Proceedings of the Combustion Institute, vol. 33, no. 2, pp. 1715-1722, 2011.

[39] C. Di Blasi, "Modeling chemical and physical processes of wood and biomass pyrolysis," Progress in Energy and Combustion Science, vol. 34, no. 1, pp. 47-90, 2008. 


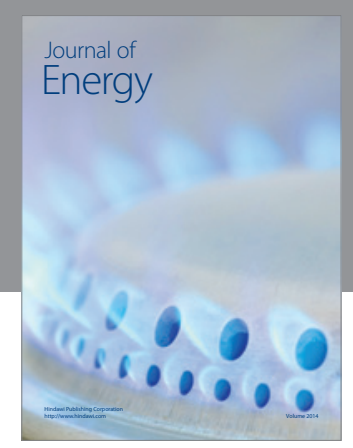

Journal of

Industrial Engineering
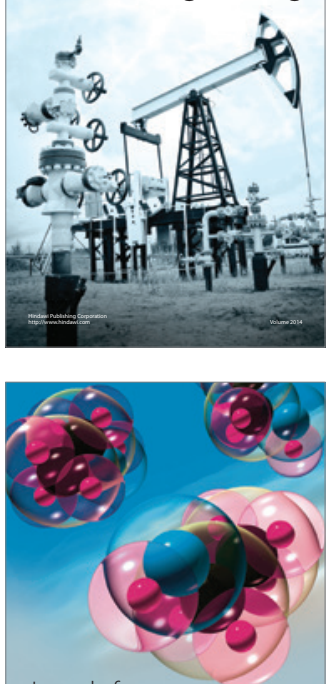

Fuels
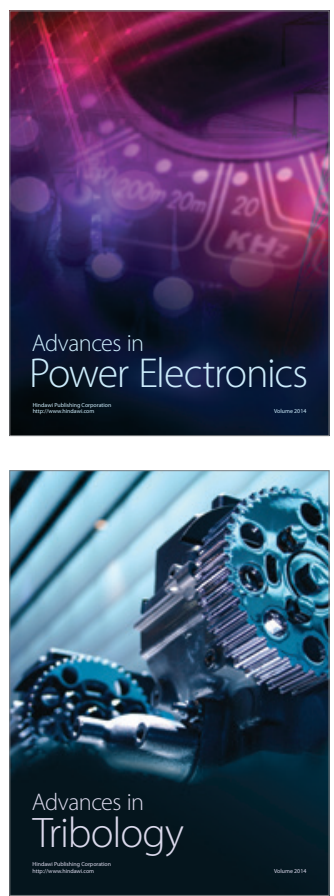

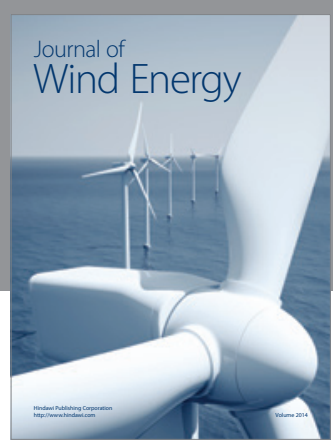

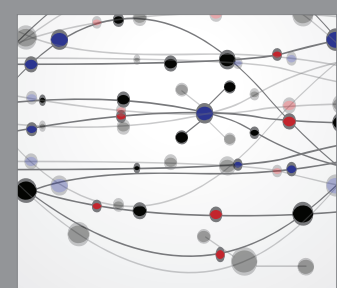

The Scientific World Journal

Submit your manuscripts at http://www.hindawi.com

Journal of

Structures
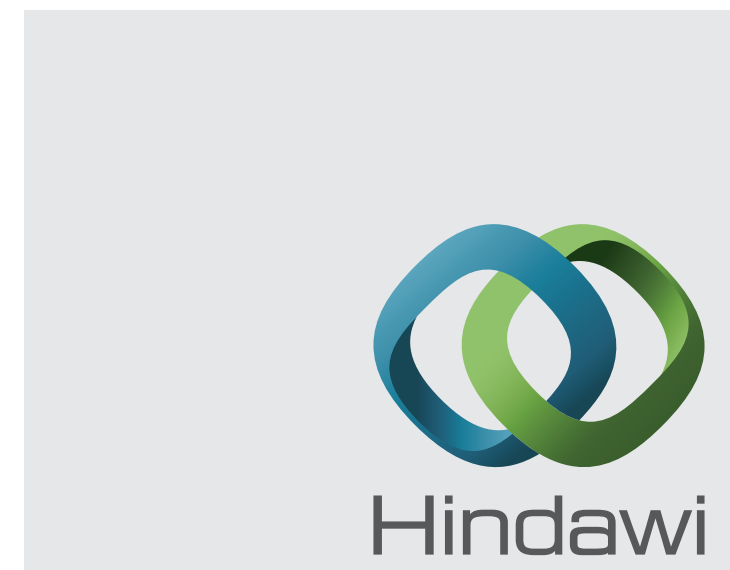

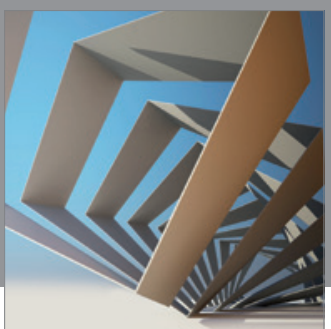

Rotating

Machinery
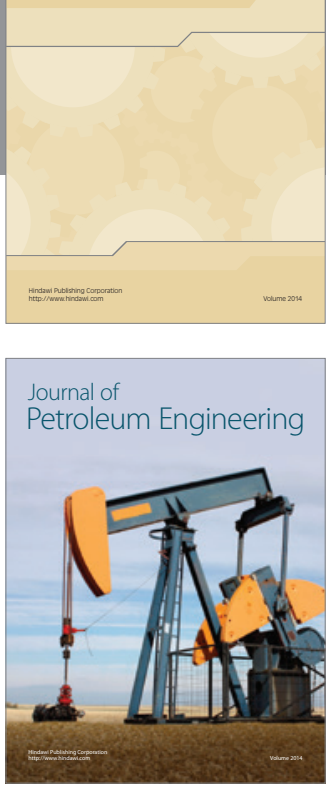

Journal of

Solar Energy
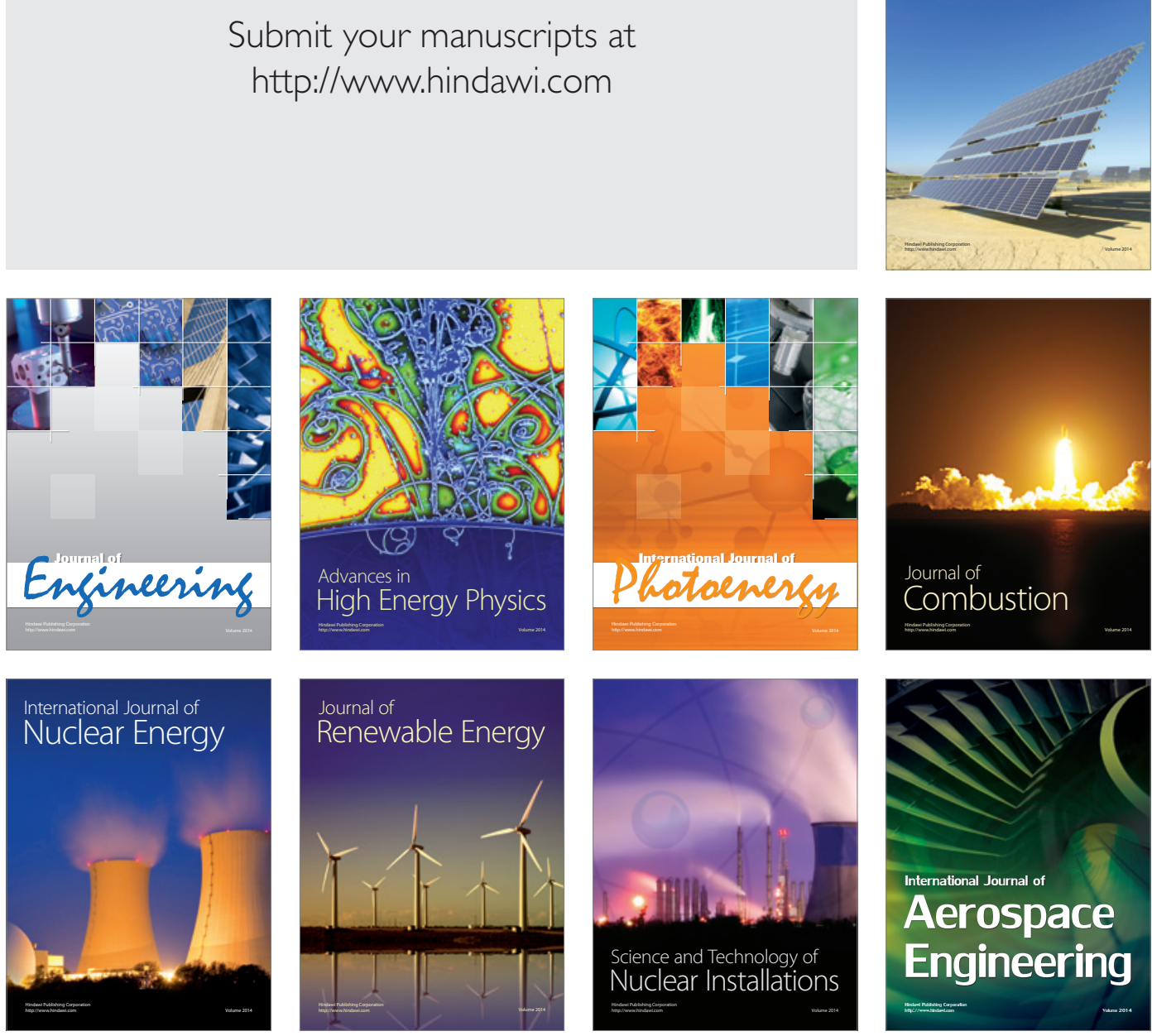